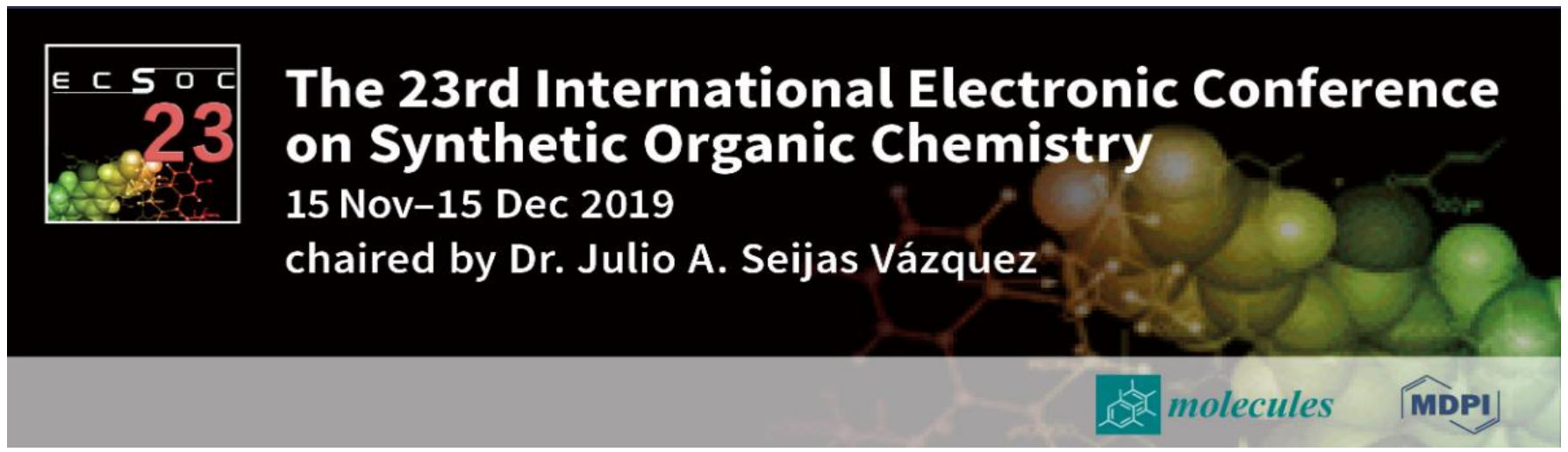

\title{
Thiohydantoins from vanillin and its derivatives - Synthesis and Characterization
}

\author{
Petar Stanić, ${ }^{1}$ Marija Živković, ${ }^{2}$ Zoran Ratković, ${ }^{1}$ Jovana Muškinja, ${ }^{3}$ Biljana Šmit ${ }^{3}$ * \\ ${ }^{1}$ University of Kragujevac, Faculty of Science, Department of Chemistry, Radoja Domanovića 12, 34000 \\ Kragujevac, Serbia \\ ${ }^{2}$ University of Kragujevac, Faculty of Medical Sciences, Svetozara Markovića 69, 34000 Kragujevac, Serbia \\ ${ }^{3}$ University of Kragujevac, Institute for Information Technologies Kragujevac, Jovana Cvijića bb, 34000 \\ Kragujevac, Serbia \\ *correspondence: biljana.smit@pmf.kg.ac.rs
}

\begin{abstract}
Hydantoins and their sulfur containing analogues, thiohydantoins, are an important and interesting moiety. They represent a big group of structurally diverse compounds with intriguing physical, chemical and biological properties, which enabled them to be used in therapy, medicine in general, material science and industry.

With the goal of broadening the set of potentially applicable hydantoin derivatives, we have synthesized a series of 2-thiohydantoins from vanillin and its derivatives, which themselves posses interesting biological properties. All compounds were fully characterized by NMR and IR spectroscopy. The compounds will be subjected to intensive biological screening to determine their biological properties and application opportunities.
\end{abstract}

Keywords: thiohydantoins; synthesis; vanillin 


\section{Introduction}

Hydantoins and thiohydantoins are five-membered heterocycles with various interesting physical and chemical properties. [1] They have recently got huge attention due to the structural diversity of their derivatives and the wide set of biological properties and applications in medicinal chemistry. [2,3]

Arylidene hydantoin derivatives are well known for their biological activities (Figure 1), such as antimicrobial [4] and anti-cancer [5]. N3-substituted hydantoins have also been intensively studied for their potential biological activities [6,7]. With all this in mind, we present a synthesis of a series of 3substituted 2-thiohydantoins from vanillin and its derivatives. Because hydantoins are such valuable scaffolds, the preparation of these novel compounds is of great interest to synthetic organic chemistry and could lead to potentially bioactive molecules.

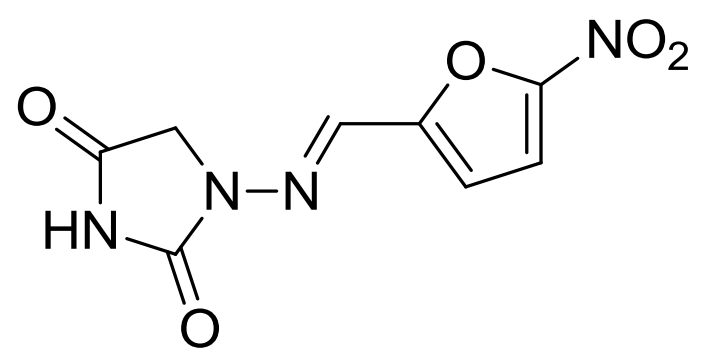

Figure 1. Nitrofurantoin (commertial name Furadantin $($ )), used as an anti-bacterial agent

\section{Results and discussion}

A series of ten 2-thiohydantoins have been synthesized from vanillin and its derivatives, nine of which are novel. Vanillin derivatives were prepared by alkylation of the free phenolic group with corresponding alkyl halides (Scheme 1), following the previously described procedure [8].

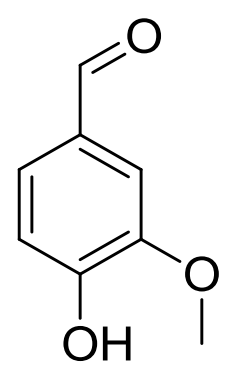

$1 \mathrm{a}$

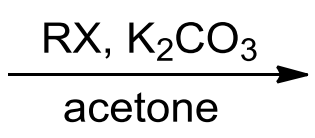

$1 \mathrm{c}-\mathrm{j}$

Scheme 1. Synthesis of O-alkyl vanillin derivatives 
The thiohydantoins themselves are synthesized according to a previously described protocol involving thiosemicarbazide [9]. The thiosemicarbazone generated in the reaction then reacts with ethyl chloroacetate in the presence of anhydrous sodium acetate, producing the desired thiohydantoin (Scheme 2). The compounds were obtained in moderate to high yields (Table 1) and were all fully characterized by NMR and IR spectroscopy.

The preparation of these compounds is not only important for fundamental research in synthetic organic chemistry and the better understanding of hydantoin chemistry itself, but also for the search for compounds with potential medicinal application, which will be explored trough further extensive biological evaluations.

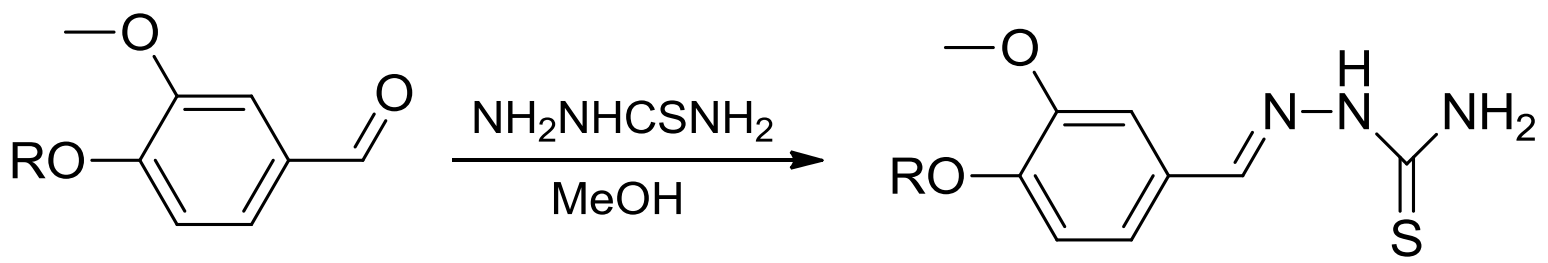

$1 \mathrm{a}-\mathrm{j}$

2a-j
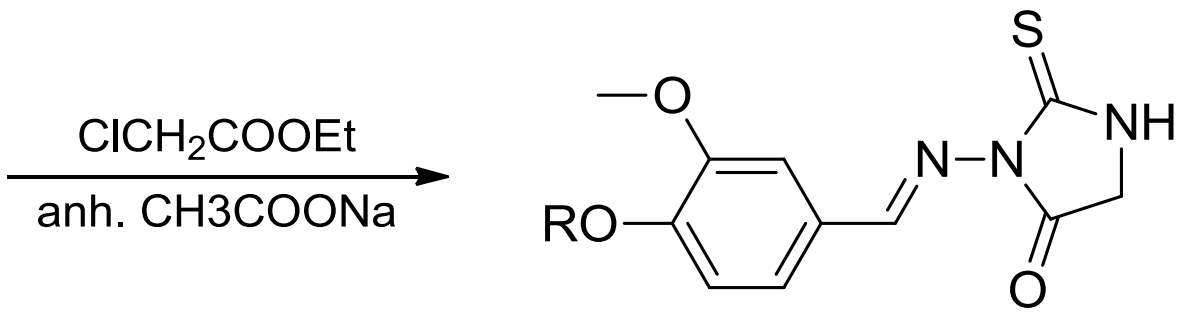

$3 a-j$

Scheme 2. Synthesis of 2-thiohydantoins from vanillin and its derivatives

Table 1. Structure and yields of the synthesized vanillin derived thiohydantoins

Entry Substrate Yield (\%)


d<smiles>CCCOc1ccc(C=O)cc1OC</smiles>

e<smiles>COc1cc(C=O)ccc1OC(C)C</smiles>

f<smiles>C=C(C)COc1ccc(C=O)cc1OC</smiles>

g

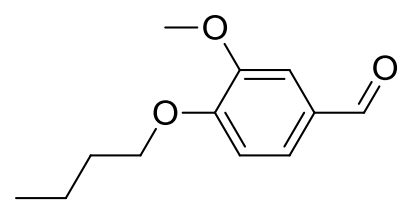

$\mathbf{h}$<smiles>COc1cc(C=O)ccc1OCC(C)C</smiles>

i
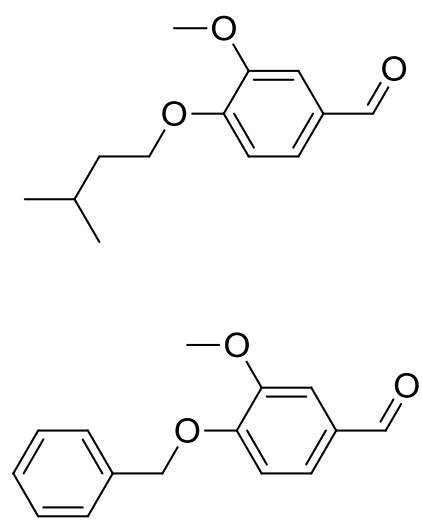<smiles>CCCOc1ccc(/C=N/N2C(=O)CNC2=S)cc1OC</smiles>

\section{Experimental}

\section{General}

All chemicals and reagents, including compounds $\mathbf{1 a}$ and $\mathbf{1 b}$ are commercially available and were used as received without further purification. Solvents were purified by distillation prior use. Anhydrous methanol 
was prepared by standard drying procedure. Thin-layer chromatography (TLC) was performed on silica gel on Al plates, layer thickness $0.2 \mathrm{~mm}$. IR spectra were recorded on a Perkin-Elmer FT-IR spectrometer

model Spectrum One. ${ }^{1} \mathrm{H}$ and ${ }^{13} \mathrm{C}$ NMR spectra were recorded on a Varian Gemini 2000 NMR spectrometer in DMSO as solvent.

General procedure for the preparation of vanillin $O$-alkyl derivatives $\mathbf{1 c}$-j

A mixture of vanillin $(0.01 \mathrm{~mol})$, an appropriate alkyl halide $(0.025 \mathrm{~mol})$ and $\mathrm{K}_{2} \mathrm{CO}_{3}(4.5 \mathrm{~g}$, anhydrous $)$ was heated under reflux for 3 hours. The cooled mixture was poured into water, extracted with ethyl acetate, washed with water and dried over $\mathrm{Na}_{2} \mathrm{SO}_{4}$. The solvent was removed in vacuo and the residue was separated by column chromatography with hexane/EtOAC (from 3:1 to 6:1) as eluent, giving the products 1c-j.

General procedure for the preparation of thiosemicarbazones $2 a-j$

Aldehydes 1a-j $(0.01 \mathrm{~mol})$ and thiosemicarbazide $(0.01 \mathrm{~mol})$ were heated under reflux in methanol (30 $\mathrm{ml}$ ) for 3 hours and then cooled. The solid formed was filtered off, dried and purified by re-crystallization with methanol, giving thiosemicarbazones $\mathbf{2 a - j}$.

General procedure for the preparation of thiohydantoins $\mathbf{3 a - j}$

A mixture of $\mathbf{2 a - j}(0.01 \mathrm{~mol})$, ethyl chloroacetate $(0.01 \mathrm{~mol})$ and anhydrous sodium acetate $(0.03 \mathrm{~mol})$ was heated under reflux in methanol $(50 \mathrm{ml})$ for 6 hours. The mixture was cooled and poured into cold water. The resulting solid was filtered off, washed with hot water, dried and purified by re-crystallization with hot methanol.

\section{Conclusions}

A series of ten 2-thiohydantoins were synthesized from vanillin and its derivatives, nine of which are novel. The compounds were obtained in moderate to high yields and were fully characterized by NMR and IR spectroscopy. Since both, N3-substituted and arylidene substituted hydantoins, exhibit various biological activities, this work will serve as a useful footnote in the search for more biologically active and 
potentially applicable compounds. The potential of their medicinal application will be thoroughly explored through intensive biological evaluations.

\section{Acknowledgements}

The authors are grateful to the Ministry of Education, Science and Technological Development of the Republic of Serbia (Project numbers 172016, 172034 and 172036) for financial support.

\section{References}

1. E. Ware, Chem. Rev., 1950, 46, 403-470

2. L. Konnert, F. Lamaty, J. Martinez, E. Colacino, Chem. Rev., 2017, 117, 13757-13809

3. S. Cho, S-H. Kim, D. Shin, Eur. J. Med. Chem., 2019, 164, 517-545

4. E. Szymanska, K. Kiec-Kononowicz, Il Farmaco, 2002, 57, 355-362

5. J. Handzlik, G. Spengler, B. Mastek, A. Dela, J. Molnar, L. Amaral, K. Kiec-Kononowitz, Acta Pol. Pharm., 2012, 69,149-56

6. F. Nique, S. Hebbe, N. Triballeau, C. Peixoto, J.-M. Lefrancois, H. Jary, L. Alvey, M. Manioc, C. Housseman, H. Klaassen, et al., J. Med. Chem., 2012, 55, 8236-8247

7. A. Martinez, M. Alonso, A. Castro, I. Dorronosoro, J. L. Gelpi, F. J. Luque, C. Perez, F. J. Moreno, J. Med. Chem., 2005, 48, 7103-7112

8. A. R. Katritzky, Q. Long, H. He, Qiua, A. L. Wilcox, Arkivoc, 2006, vi, 868-875

9. M. E. Abd El-Fattah, A. H. Soliman, H. H. Abd Allah, in Proceedings of the 14th International Electronic Conference on Synthetic Organic Chemistry (ECSOC-14), CDROM, MDPI, Basel, 2010, Abstract No. B024 